\title{
Effects of oxytocin and vasopressin on electrical and mechanical activity of the rat epididymis in vitro
}

\author{
Ulla-Marjut Jaakkola and A. Talo \\ Laboratory of Animal Physiology, University of Turku, 20500 Turku 50, Finland
}

\begin{abstract}
Summary. Electrical and mechanical activity of the caput and cauda epididymidis were recorded at measured distances from the beginning and end of the epididymal duct. Oxytocin had no significant effects on the caput or cauda. Vasopressin increased significantly the frequency of the electrical activity in the caput and cauda and frequency of contractions and basal tension of the cauda at a dose of $4 \times 10^{-1}$ $\mathrm{mU} / \mathrm{ml}$ and even more at a dose of $4 \mathrm{mU} / \mathrm{ml}$. The maximal increase in frequency of activity was $70-90 \%$ in the cauda and about $35 \%$ in the caput.
\end{abstract}

\section{Introduction}

Oxytocin stimulates the muscles of the uterus and mammary glands and vasopressin also stimulates smooth muscles. Various authors (Peeters \& Debackere, 1963; Sharma, Fitzpatrick \& Ward, 1972; Sharma \& Hays, 1973) have shown that oxytocin and vasopressin are released into the blood of the male during ejaculation. Oxytocin administration increases the sperm concentration and output by the testis in vivo (Voglmayer, 1975), probably by increasing the spontaneous contractions of the seminiferous tubules (Niemi \& Kormano, 1965). The frequency, weight and sperm content of spontaneous ejaculates are reduced after copulation but treatment with oxytocin partly offsets these changes, particularly the number of spermatozoa in the ejaculates (Agmo, Andersson \& Johansson, 1978). The oxytocin and vasopressin released during ejaculation might therefore have stimulatory effects on the spontaneous contractions of the smooth muscles of the epididymal duct and accelerate the transport of spermatozoa into the distal cauda epididymidis.

The effects of oxytocin and vasopressin on the epididymal smooth muscles are not well known. The earlier studies were done with intraluminal catheters located at the epididymal end of the vas deferens (Melin, 1970; Knight, 1974; Hib, 1975, 1977). The caput epididymidis differs from the cauda epididymidis histologically, biochemically, functionally (Orgebin-Crist, 1969; Riar, Setty \& Kar, 1973) and by its myoelectrical activity (Talo, Jaakkola \& MarkkulaViitanen, 1979). The present study therefore examined the effects of oxytocin and vasopressin on the electrical activity of the caput and cauda epididymidis and on the mechanical activity of the cauda.

\section{Materials and Methods}

Experiment 1. Twenty Sprague-Dawley male rats were caged in groups of 6-8 apart from females and were killed by decapitation under a light ether anaesthesia. The testis, epididymis and a short portion of the vas deferens were removed quickly into oxygenated $\left(95 \% \mathrm{O}_{2}, 5 \%\right.$ 
$\mathrm{CO}_{2}$ ) Ringer solution (see below) at room temperature $\left(22^{\circ} \mathrm{C}\right)$. The connective tissue capsule of the epididymis was removed and a $5-\mathrm{cm}$ long portion of the cauda, at about $20 \mathrm{~cm}$ from the end of the epididymal duct, and of the caput, at about $50 \mathrm{~cm}$ from the beginning of the epididymal duct, were uncoiled by careful dissection. Electrical activity was recorded with suction electrodes (Talo \& Hodgson, 1978) which had an outer tip diameter of 100-250 $\mu \mathrm{m}$ connected to a Grass 6-channel polygraph recorder. Three electrodes were placed on the cauda and three on the caput. A common reference electrode $(\mathrm{Ag} / \mathrm{AgCl})$ and ground electrode were placed in the chamber. The water-jacketed chamber contained $100 \mathrm{ml}$ modified Ringer solution $(154 \mathrm{mM}-\mathrm{NaCl}, 5.6$ mM-KCl, $0.12 \mathrm{mM}-\mathrm{MgCl}_{2}, 2.2 \mathrm{mM}-\mathrm{CaCl}_{2}, 5.9 \mathrm{~mm}-\mathrm{NaHCO}_{3}, 2.5 \mathrm{mM}$-glucose; $\left.\mathrm{pH} 7.2\right) \mathrm{kept}$ at a temperature of $34 \pm 0.5^{\circ} \mathrm{C}$. After $30 \mathrm{~min}$ for equilibration, 10 doses of oxytocin (Syntocinon: Sandoz AG, Basel, Switzerland) were added at 5-min intervals to the chamber fluid to give cumulatively increasing solution concentrations. Vasopressin (Postacton: Ferring AB, Malmö, Sweden) was similarly used in another 10 tests.

Experiment 2. Ten rats were used. Mechanical activity was recorded from a $0.5-\mathrm{cm}$ long portion removed at a mean distance of $31 \pm 5 \mathrm{~cm}$ from the junction of the epididymis and the vas deferens for the vasopressin tests and at $22 \pm 6 \mathrm{~cm}$ for the tests with oxytocin (Oxytocin: Sigma Chemical Co., St Louis, Missouri 63178, U.S.A.). The drugs were added as cumulative dose concentrations as in Exp. 1, except that the chamber contained $50 \mathrm{ml}$ Ringer solution. The isometric recordings of contractions were made with the Grass FT 0.3 mechano-electrical transducer. The frequency of contractions was calculated for $3 \mathrm{~min}$ after every drug dose. The results were tested with the Student's $t$ test.

\section{Results}

Oxytocin had very little effect on the frequency or amplitude of the electrical activity of the caput or cauda epididymidis. In some cases immediately after the drug dose one or two extra action potentials could be seen, but they had no effect on the mean frequencies. The highest concentration $(100 \mathrm{mU} / \mathrm{ml})$ had a weak stimulatory effect on the frequency of the cauda epididymidis, but this was not statistically significant. The frequencies of the contractions of the cauda epididymidis measured mechanically (Text-fig. 1a) were similar to the electrical activity frequencies and there were no significant effects on the baseline of tension or amplitude of contractions (Text-fig. 2a).

Vasopressin increased the frequency of the electrical activity in the caput (Text-fig. 3a) and cauda (Text-fig. 3b), significantly so with doses of $4 \times 10^{-1}$ and $4 \mathrm{mU} / \mathrm{ml}(P<0.01$ and $P<$

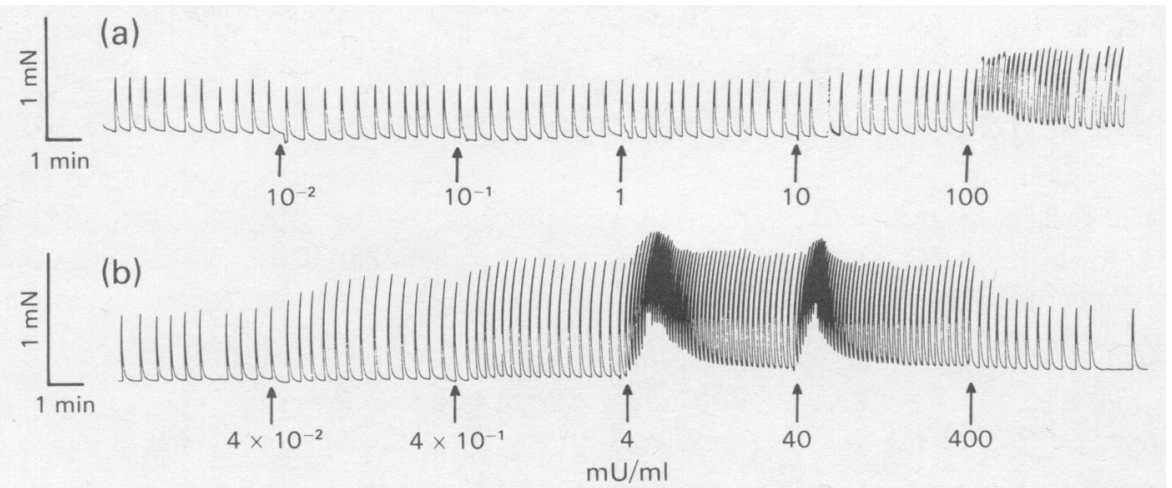

Text-fig. 1. Mechanical activity of the rat cauda epididymidis after treatment with (a) oxytocin and (b) vasopressin. 

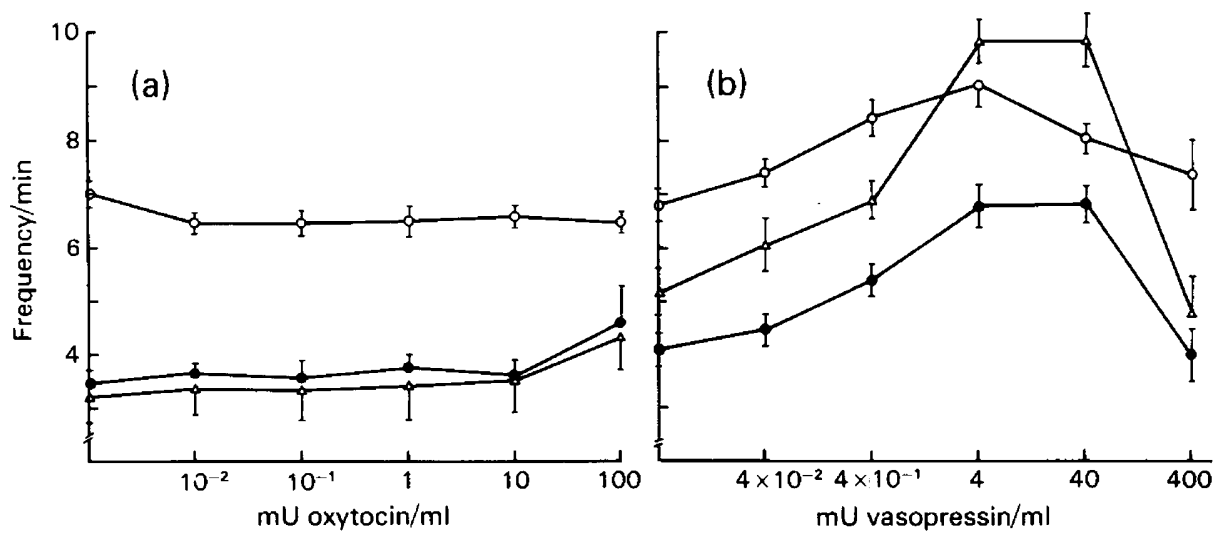

Text-fig. 2. Effects of (a) oxytocin and (b) vasopressin on the frequency of the electrical activity of the caput $(O)$ at about $50 \mathrm{~cm}$ from the beginning of the epididymal duct and of the cauda (O) at about $20 \mathrm{~cm}$ from the end of the epididymal duct, and of the mechanical activity of the cauda at the same region $(\triangle)$.

0.001 , respectively). In the caput, but not the cauda, the frequency of the electrical activity decreased at the concentration of $40 \mathrm{mU} / \mathrm{ml}$. The mechanical activity of the cauda responded to vasopressin more effectively than did the electrical activity: the maximal increase in frequency of contractions was over $90 \%$ compared with about $70 \%$ for the electrical activity. The maximal increase in frequency of the electrical activity of the caput was only about $35 \%$ (Text-fig. $2 b$ ). The mechanical recordings showed that vasopressin increased the basal tension at higher concentrations (Text-fig. 1b) and the highest vasopressin concentration sometimes caused tetanus in the tissue.

\section{Discussion}

The earlier studies of the effects of neurohypophysial hormones on the epididymis were done at the epididymal end of the vas deferens, or on a long portion of the epididymis, and the results were generalized for the whole epididymal duct although this is very long in the rat (about 3.6 $\mathrm{m})$. In this study a precise area was used for recording and two different methods were used to study the cauda epididymidis. The results of both methods agree well with each other, although the frequency of contractions of the cauda exposed to vasopressin was higher than that of the electrical activity, perhaps because mechanical activity was recorded at about $10 \mathrm{~cm}$ nearer to the end of the epididymal duct than was electrical activity. Our earlier study showed a steep decline in frequency of spontaneous activity in this area (Talo et al., 1979). Electrical recording only was used in the caput because of the thinness of its muscle layers. The pretreatment activities of the caput and cauda agree well with those of the study of Talo et al. (1979), when the $2.5^{\circ} \mathrm{C}$ lower temperature of the present study is considered (Jaakkola \& Talo, 1980).

The concentration $\left(4 \times 10^{-1} \mathrm{mU} / \mathrm{ml}\right)$ of vasopressin that increased significantly the frequency of the electrical and mechanical activity in the caput and cauda was about the same as that used by Hib (1975) to increase the frequency and basal tension of the activity of the distal end of the epididymis of the mice. But the dose of vasopressin which induced the maximal effect was higher in our study $(4 \mathrm{mU} / \mathrm{ml})$ than in that of $\mathrm{Hib}(1975)(1 \mathrm{mU} / \mathrm{ml})$. These are probably species differences in sensitivity to neurohypophysial hormones as shown by studies with the rabbit (Melin, 1970) and the ram (Knight, 1974). The effects of oxytocin on the vas deferens and epididymis may also vary with species and with the area of the epididymis tested (Melin, 1970). 
(a)
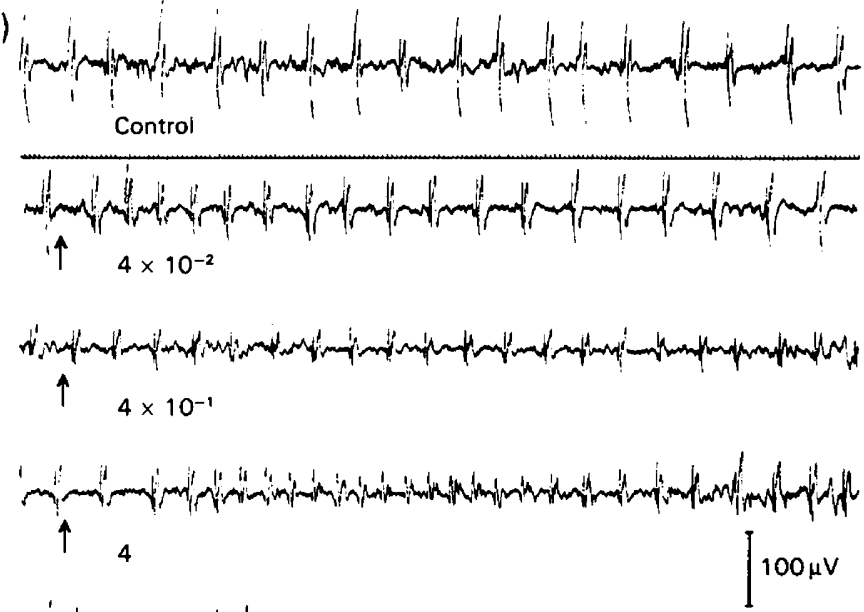

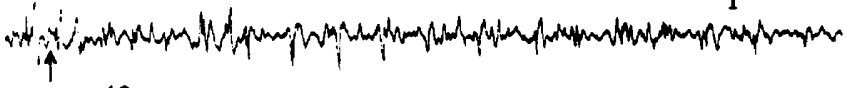

40

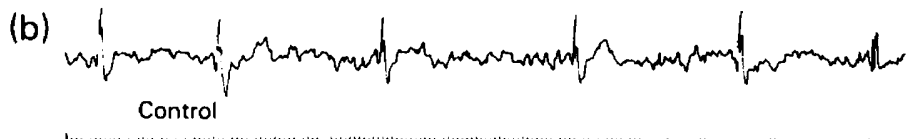

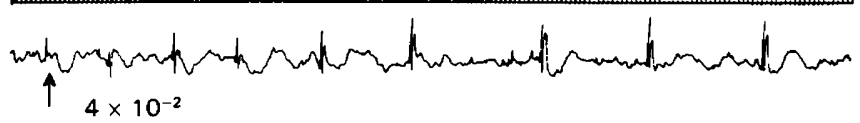

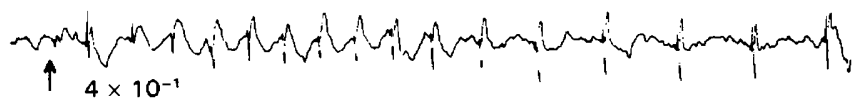

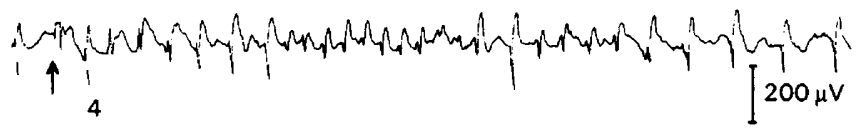

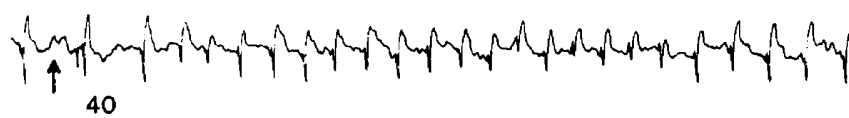

Text-fig. 3. Electrical activity of the (a) caput and (b) cauda epididymidis after vasopressin doses. The arrows show the time when the drug was added. The concentrations are in $\mathrm{mU} / \mathrm{ml}$. Pre-amplifier time constant, $0.3 \mathrm{~Hz}$ in (a) and $0.15 \mathrm{~Hz}$ in (b).

In the rat, oxytocin increased the frequency and the amplitude and the basal tension of contractions of the distal end of the epididymis in vivo (Hib, 1977). We found no significant effects on the mechanical or electrical activity of the cauda at a distance of about $20 \mathrm{~cm}$ from the end of the epididymal duct or in the caput at a distance of about $50 \mathrm{~cm}$ from the beginning of the epididymal duct. There may be differences in the regulation of the spontaneous activity of the cauda and caput because the strong adrenergic innervation found in the cauda is lacking in the caput (Baumgarten, Holstein \& Rosengren, 1971). The stronger response to vasopressin found in the cauda than in the caput may have been caused by heterogeneous distribution of the receptors sensitive to neurohypophysial hormones. A different sensitivity to these hormones has been found earlier between proximal and distal parts of the vas deferens of the male rabbit (Melin, 1970). During ejaculation the neurohypophysial hormones released simultaneously 
(Heller, 1961) may have complementary effects on the male genital tract: vasopressin increases the contractility of the epididymal duct, while oxytocin affects the contraction of the seminiferous tubules (Niemi \& Kormano, 1965), and the sperm output by the testis (Voglmayer, 1975).

This study was supported by the Emil Aaltonen Foundation and the Academy of Finland.

\section{References}

Ȧmo, A., Andersson, R. \& Johansson, C. (1978) Effect of oxytocin on sperm numbers in spontaneous rat ejaculates. Biol. Reprod. 18, 346-349.

Baumgarten, H.G., Holstein, A.F. \& Rosengren, E. (1971) Arrangement, ultrastructure and adrenergic innervation of smooth musculature of the ductuli efferentes, ductus epididymis and ductus deferens of man. Z. Zellforsch. mikrosk. Anat. 120, 37-79.

Heller, H. (1961) Occurrence, storage and metabolism of oxytocin. In Oxytocin, pp. 3-23. Eds R. CaldeyroBarcia \& H. Heller. Pergamon Press, London.

Hib, J. (1975) Epididymal contractility in vitro: effects of drugs. Acta physiol. latinoAm. 25, 233-234.

Hib, J. (1977) The in vivo effects of oxytocin and vasopressin on spontaneous contractility of the rat epididymis. Int. J. Fert. 22, 63-64.

Jaakkola, U.-M. \& Talo, A. (1980) Effect of temperature on the electrical activity of the rat epididymis in vitro. $J$. Thermal Biol. 5, 207-210.

Knight, T.W. (1974) A qualitative study of factors affecting the contractions of the epididymis and ductus deferens of the ram. J. Reprod. Fert. 40, 19-29.

Melin, P. (1970) Effects in vivo of neurohypophysial hormones on the contractile activity of accessory sex organs in male rabbits. J. Reprod. Fert. 22, 283-292.

Niemi, M. \& Kormano, M. (1965) Contractility of the seminiferous tubule of the postnatal rat testis and its response to oxytocin. Annls Med. exp. Biol. Fenn. 43, 40-42.

Orgebin-Crist, M.C. (1969) Studies on the function of the epididymis. Biol. Reprod. 1, 155-175.

Peeters, G. \& Debackere, M. (1963) Influence of massage of the seminal vesicles and ampullae and of coitus on water diuresis of the ram. J. Endocr. 26, 249-258.

Riar, S.S., Setty, B.S. \& Kar, A.B. (1973) Studies on physiology and biochemistry of mammalian epididymis: histology, enzyme and electrolyte composition of epididymis - a comparative study. Indian J. exp. Biol. 11, 365-380.

Sharma, O.P. \& Hays, R.L. (1973) Release of an oxytocic substance following genital stimulation in bulls. J. Reprod. Fert. 35, 359-362.

Sharma, S.C. Fitzpatrick, R.J. \& Ward, W.R. (1972) Coital-induced release of oxytocin in the ram. $J$. Reprod. Fert. 31, 488-489.

Talo, A. \& Hodgson, B.J. (1978) Spike bursts in rabbit oviduct. I. Effect of ovulation. Am. J. Physiol. 234, E430-E438.

Talo, A., Jaakkola, U.-M. \& Markkula-Viitanen, M. (1979) Spontaneous electrical activity of the rat epididymis in vitro. J. Reprod. Fert. 57, 423-429.

Voglmayer, J.K. (1975) Output of spermatozoa and fluid by testis of the ram and its response to oxytocin. $J$. Reprod. Fert. 43, 119-122.

Received 10 September 1980

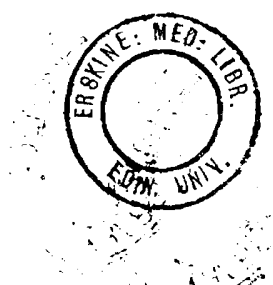

